\title{
Arquiviagem pelo eu-arquivo Vitoriamario
}

Lúcio de Araújo*

Universidade de Brasília

\begin{abstract}
Resumo
0 artigo propõe uma arquiviagem pelo eu-arquivo Vitoriamario denominado Apodrece e vira adubo. Nele, lanço o olhar em aberturas e diferenças contidas na produção desse eu-plural compartilhado. Ao passo que este cosmos me atravessa, como um levante sobre poeira o agito. Assim, proponho aguçar o faro de autor, artista e criatura, com o desejo de provocar excitação pelas multiplicidades moleculares de eus-retóricos. Uma investigação que sugere 0 trânsito por fissuras nas relações de autoria, geradas por uma poética de arquivo.
\end{abstract}

\section{Palavras-Chave}

Arquiviagem; autoria; arquivo; poética; vitoriamario.

\section{Archivoyage through Vitoriamario's self-archive Abstract}

This article proposes an archivoyage through Vitoriamario's self-archive entitled Apodrece e vira adubo. I take a look on gaps and differences contained in the production of this shared self-plural. While this cosmos passes through me, as an uprising on the dust I shake it. Thus, I propose to sharpen the author, artist and creature senses, in order to cause excitement by molecular multiplicities of selvesrhetoricians. An investigation that suggests a transit through fissures at the authorship relations generated by an archive poetics.

\section{Keywords}

Archivoyage; authorship; archive; poetics; vitoriamario.

\footnotetext{
" Mestrando no Programa de Pós-graduação em Arte do Instituto de Artes da Universidade de Brasília (UnB), linha de pesquisa Poéticas Contemporâneas, sob orientação da Dra. Karina e Silva Dias. Especialista em História da Arte Moderna e Contemporânea (Embap), graduado em Educação Artística - Artes Plásticas (UFPR). Bolsista CAPES. Websites: http://arquiviagem.net; http://luciodearaujo.wordpress.com/; http://transitos.org.
} 
"Outras vezes eu imaginava que um gêmeo invisível andava ao meu lado, por assim dizer o inverso de uma sombra."

(W. G. Sebald - Austerlitz)

Estas páginas propõem uma arquiviagem. Nelas, lanço o olhar para aberturas e diferenças contidas no arquivo do mito pop Vitoriamario. Ao passo que este cosmos me atravessa, como um levante sobre poeira 0 atravesso. Assim, proponho aguçar o faro do eu-autor contido no eu-artista. O desejo aqui é provocar excitação pelas multiplicidades moleculares de eus-retóricos. "Todos os discursos que são providos da função autor comportam esta pluralidade de eus" (Foucault, 1992: 70). Pretendo catalisar variações, exponenciar deslocamentos discursivos que propiciem o surgimento de outros lugares de (não-)fala, outros-eus, eus-devires. No agenciamento do sujeito, busco abrir caminhos ao desenvolvimento da poética do duplo. Uma caleidoscópica poética de extração de pares, em cada nova referência aceita, cada novo diálogo a ser realizado, cada contato, cada esbarrar no outro "em variação perspectiva e multiplicação especular" (Pelbart, 1998: xix). Deste modo, adoto uma investigação que sugere o trânsito por fissuras entre o eu-artista e o eu-criatura.

Quem é Vitoriamario? A que vem? Que arte propõe? Quais seus desejos? $\mathrm{Na}$ tentativa de resposta, eu me aproximo de uma poética das personas embebida no que Vitoriamario denomina de crise do indivíduo (2002b), poética esta relacionada à crise da representação presente no vazio de Mallarmé, no abandono da palavra de Rimbaud, nas obras de Beckett, Blanchot, Barthes, Foucault e Agamben, e à crise do autor e do que resta das tensões de poder dos agentes dos enunciados. Assunto demasiado complexo, abordado aqui brevemente, mas que serve como ponto de partida à arquiviagem em Vitoriamario.

Beckett verifica que, ao entrar em contato com a realidade inominável, a linguagem entra em colapso. A anomia, presente na origem dos silêncios 
significantes em seu teatro, aponta a falência do dizer. Uma vez nessa condição, o ser autor se vê condenado a uma fala impotente. Disso, Blanchot elabora:

O inominável, um ser sem ser que não pode nem viver, nem morrer, nem cessar, nem começar, o lugar vazio em que fala a ociosidade de uma fala vazia e que é recoberta, bem ou mal, por um Eu poroso e agonizante (2005: 312).

$\mathrm{Na}$ esteira desse pensamento, Foucault e Barthes propõem a dessacralização da figura do autor (Figueiredo, 2014: 184) pelo viés da abertura. O primeiro através do arquivo, enquanto sistema de enunciados, e do discurso como acontecimento (Foucault, 2009), o segundo pela morte do autor, enfatizando a recepção, ou seja, o leitor como elemento chave que atravessa e é atravessado pelo texto (ou arte), na propulsão de outros significados, na diferença. "O texto é plural (...); um plural irredutível" (Barthes, 1988: 74).

A partir dos muçulmanos sobreviventes de Auschwitz, Agamben desloca a questão do autor ao testemunho, o qual se estabelece no hiato entre o dito e 0 não dito. Próximo ao inominável de Beckett e problematizando os escritos de Foucault, o testemunho seria um estranho autor que funda sua língua entre a possibilidade e a impossibilidade de falar, entre o enunciável e o não enunciável, entre 0 arquivável e o não arquivável. Esse lugar é identificado pelo autor como o que resta. Para Agamben, a complexa tarefa de adentrar no universo do testemunho se dá a partir dessa lacuna, em saber "escutar o não dito" (Agamben, 2008: 21).

Ao demonstrar inconformismo com a realidade, Vitoriamario decide lutar contra as muitas formas de resignação. Encontra no paradoxo seu caminho, suas ações se dão pelo gesto manco, pela farsa ingênua e descarada, pela pilhagem e desgaste da autoria. Um jogo que a cada lampejo (anti-)heroico alucina e extravasa em eu-vitoriamario. Suas ações são curto-circuitos nos sistemas de cristalização produzidos pelo 
nominável. Como tática para anular o autoritarismo e desmascarar as diversas faces da repressão, o eu-vitoriamario se coletiviza e se singulariza no incerto, pelo código aberto. Entidade pública, nome fantasia, seu eumúltiplo dispensa protocolos e requerimentos de permissão de uso. Para fins libertários se dispõe à diferença (como licença de uso). Prescinde de referências e reverências. Sua atitude consiste na apropriação irrestrita, na manipulação enquanto invenção. Atrevido, Vitoriamario busca brechas, visa transpor aquilo que em um primeiro tempo impressiona (ou se supõe) como rígido. Vitoriamario é o próprio pandemônio desprovido de contornos.

Em meio à convulsão social, Vitoriamario atua por doses de confusão. Em suas táticas de guerrilha, considera diversas versões de realidade a fim de elaborar situações de presentificação. Em Rumo ao desconhecido, um de seus diversos vídeos $C t r l+C C t r l+V$, em surto delirante o narrador declara: "Não tenho medo de descobrir que eu já não importo, eu não sirvo pra nada se eu não morrer pra virar uma lenda". Interregno de seu eu-extemporâneo, o duplo vaza por infindáveis pontos de fuga propensos ao caos inevitável.

Marcel Duchamp: Rrose Sélavy; Fernando Pessoa: Alberto Caeiro, Álvaro de Campos e Ricardo Reis, incansáveis avatares que acompanham seus propositores. Amigos imaginários, espectros virtuais, Prometeus do psiquismo desviante. Evocam artifícios de linguagem na intenção de buscar amplos jogos de sentido. Ao passo que estabelecem pistas e pontos de referência definidos, elaboram inversamente táticas de escape. Como fantasmas, tão logo assombram as consciências, dissipam-se em fumaça. Neste sentido, Vitoriamario é o mesmo que retorna e abandona, manifestase pelo desmonte previsto de si, habita o espaço daquilo que o violenta.

$\mathrm{Na}$ disputa entre memória e esquecimento, como procedimento inventivo de Vitoriamario, estão sua habilidade em investigar e manipular arquivos, 0 desembaraço na apropriação, o gesto inconsequente de embaralhamento das coisas. 
A partir dessa expertise, como cúmplice de sua produção, sintonizo-me com tal logorreia ficcional, na intenção de testemunhar ao leitor um conjunto de proposições que configuram uma poética de arquivo de artista. Ao adotar o procedimento escrita-arquivo, sugiro ocasionar conexões discursivas entre os vários eus, na confluência de espaços-tempos variados. Na face experimental desse pensamento-arquivo opto por tecer a teia que não se limita ao referente inconteste. Arquiviagem implica risco, como o de ser incompreendido ou compreendido como tautologia. Risco do qual não pretendo desviar.

\section{No atalho de Vitoriamario, arquiviagem em Apodrece e vira adubo}

O que resta de Vitoriamario é um condivíduo de caráter anárquico, identidade aberta, que se apresenta como máscara vazia de uso coletivo, cujo propósito é a insubmissão político-cultural e a banalização da moral que caduca 0 indivíduo desatento no corpo social. Na guerrilha das informações, seus desvios e devaneios são difundidos por meio de arquivos deturpados, spamails ${ }^{1}$, logins abertos, ingenuidades alegóricas, falsificações de mitos, psicografias, pajelanças, contorcionismos, dissimulações e manipulações em variadas linguagens e técnicas. Vitoriamario ocupa seu tempo o tempo todo, assim se distrai frente ao conservadorismo:

São plágios, détournments, colagens, combines, found art ou found text, intertextos e apropriações que vão de entrevistas, manifestos, textos literários, proposições artísticas, ensaios sociológicos, releases de grupos musicais e até notícias nonsense, como a suposta execução de um bruxo em plena praça pública ou do pirata que vivera no litoral do Paraná nos idos de 1900 conhecido como Vitoriamario (2002c).

Vitoriamario se alinha aos defensores da livre utilização do capital simbólico e se manifesta pela cultura das fontes de produção abertas, pela partilha,

1 Spam é o termo usado para referir-se a mensagens não solicitadas, geralmente de caráter publicitário e enviadas para um grande número de pessoas via correio eletrônico. 
pelo reuso de dados e reciclagem sígnica. Para Vitoriamario, práticas como o livre plágio e a pirataria não deveriam ser recriminadas ou hostilizadas, pois são comuns ao ato de criação e acompanham a humanidade ao longo de sua existência (Goldsmith, 2011). Como efeito dessas ideias, em sintonia com a aporia do excedente vinda de Bataille: "O sol dá sem nunca receber" (1975: 66), Vitoriamario estabelece a dádiva em seu modus operandi econômico. Tensiona os sistemas de valores, pesos éticos e padrões sociais, como nas intervenções em cédulas de dinheiro, ao indagar: "Qual seu real valor?" (Figura 1).

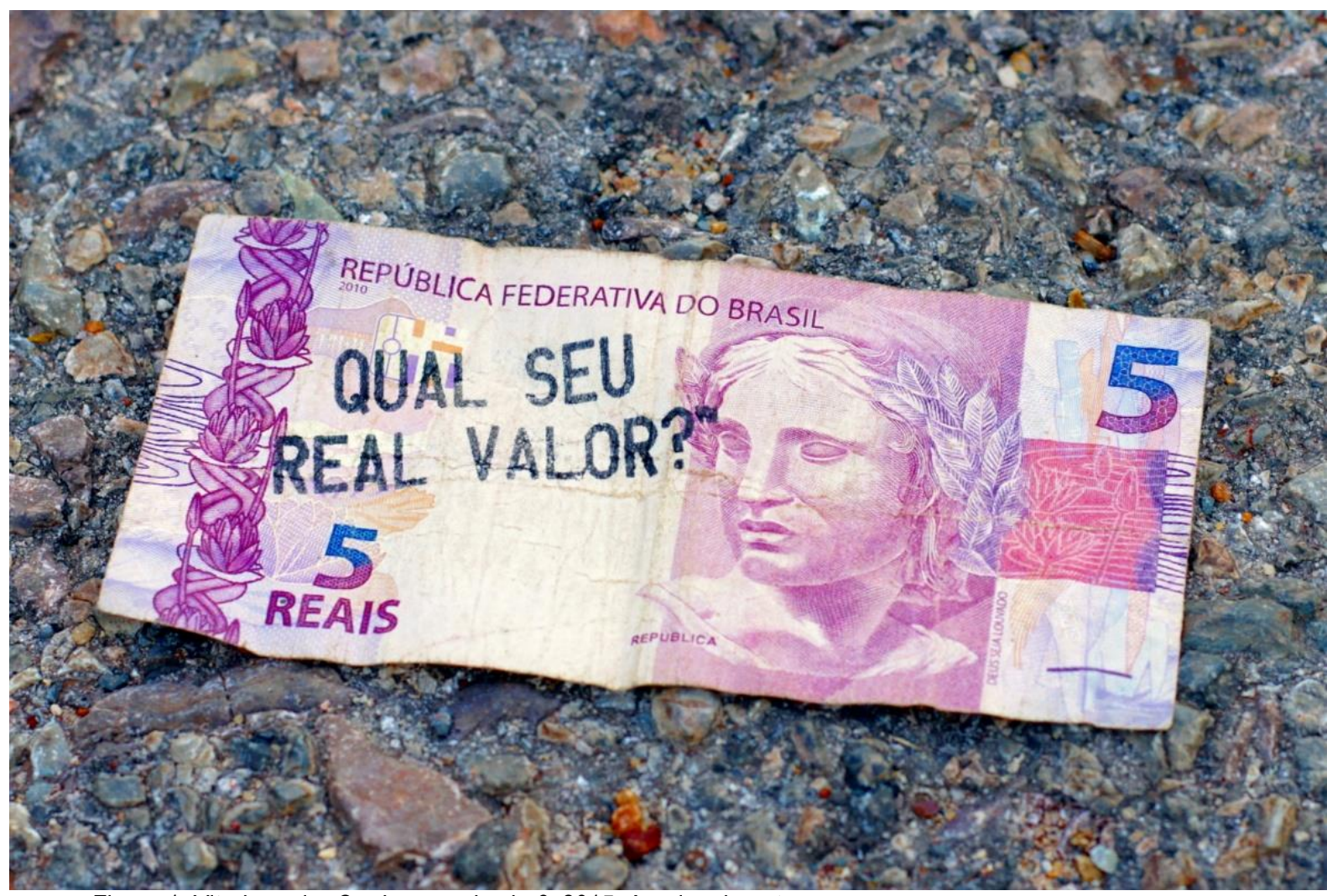

Figura 1: Vitoriamario. Qual seu real valor?. 2015. Arquivo do autor.

Ao fazer uso de um instrumento oficial capitalista, Vitoriamario encontra um meio de reflexão sobre a situação de aprisionamento ao sistema de troca com base no dinheiro. A mesma questão retorna no vídeo Zero Kelvin, na cena em que Vitoriamario é presenteado com uma espada por obediência ao Rei. O soberano diz: "Vitoriamario tem sido valente e corajoso, tal 
dignidade em defender a coroa, seus esforços merecem uma recompensa. Muito bem Vitoriamario!" (2002d). Através da ironia, Vitoriamario demonstra aversão aos sistemas de subordinação.

Em seu manifesto, Vitoriamario propõe o fim dos acordos, cobra sua dívida do sistema financeiro e de valores, dá um basta nos sistemas de significação, regozija a utopia, deseja a partilha, abala o bitolado, intrépido cutuca os vespeiros da hipocrisia. Vitoriamario luta pela vida despojada, seu eu-crítico denominado vírus de lucidez alerta sobre a paranoia sistêmica e questiona as armadilhas da linguagem:

\begin{abstract}
Música - Poesia - Arte - tudo é mentira espetáculo - subciência de alienação de seres que se alimentam da nostalgia do passado (pretérito imperfeito). Sonham com a ilusão de um Futuro (futuro do subjuntivo). E só pela poesia consegue lamber um pouco deste instante presente Vitoriamario é a ilusão de pertencer à linguagem - Vitoriamario é a ilusão de possuir um pronome e de verbalizar-se no Infinitivo escolhendo seus próprios advérbios - Vitoriamario não é arte - Vitoriamario é poesia Vitoriamario não é música e nem ciência - a ciência só existe em função da indústria - a arte só existe para mover o consumo. Não existem gênios - não existe ciência - não existe arte - só existe consumo - o que não vende é 0 ruído. $\% \& \%^{\wedge *} \&^{\wedge \wedge} \% 5 \quad 65$ e 0 ruído somos nós... \%\&\%^\&\%*\&\&^(£_Ç. Vitoriamario é um produto pseudointelectual (sim Vitoriamario é puro pleonasmo). Sem Direito autoral - Sem Discurso Moral - Influenciando as elites desta indústria do mal. Vitoriamario é um meta-substantivo-verbo-advérbio-adjetivo que pode designar um ser, um momento, uma ação uma qualidade que simplesmente significa a vitória da percepção da existência presente. O que um Vitoriamario produz não é arte ou poesia (conceitos destruídos pela indústria cultural), é simplesmente Vitoriamario produzida por Vitoriamario... e isso não implica consumo, ônus ou créditos para qualquer ego humanizado. Vitoriamario é simplesmente uma clareza de linguagem, um vírus de lucidez $|:| 808 \mathbb{8} \mu$ perante toda a paranoia conceitual do espetáculo da indústria. Sejamos todos simplesmente Vitoriamario. Aos que ainda se perguntam, Vitoriamario não significa nada e é assim que tem que ser. Chega de significar. Não queremos estética - Não queremos o mito - Não queremos linguagem Queremos um gozo doce e eterno no silêncio absoluto das pulsões (2002b)
\end{abstract}

Pirata, bruxo, mágico, louco, eu, tu, ele, nós, vós, elas. Vitoriamario é o elo no instante do fluxo-flagra pisca-piscando (Guattari, 1987: 142), energia motriz que impulsiona a pluralidade de ciclos. Como na lógica das multidões 
a morte urge no ato heroico, para que então o mito possa retornar em forma de idolatria (Carvalho, 2001) - até sua completa banalização -, Vitoriamario irrompe como possibilidade de redefinir seu espetáculo profético. Ao ser questionado sobre o seu futuro, enfatiza: "A morte espetacular!" (2002a).

Após ter anunciado seu suicídio, já em estado de decomposição foi identificado pelos algoritmos de busca em Apodrece e vira adubo², um de seus sítios publicados na web, arquivo disléxico onde estão reunidas diversas elucubrações sobre a cultura do excesso, banalização da ordem, denúncia da propriedade (sobretudo intelectual), desconstrução de comportamentos alienantes e da vulgarização das linearidades e certezas (Figura 2). Blasfema a originalidade e realça com paetê a crise do autor: "Vitoriamario confunde-te por muito menos" (2002a). De fato, a confusão é a regra em Vitoriamario, "quanto mais se lê mais confuso se fica sobre suas origens... até remetendo a séculos anteriores e a personalidades talvez imaginadas" (Antoceveiz, 2005: 48).

Ao atravessar Apodrece e Vira Adubo, tem-se inicialmente a sensação de lapso de orientação. Em certos momentos o arquivo se revela labiríntico, em outros surge como litania, um loop cuja repetição retorna em diferença. A fim de insurgir, Vitoriamario bafeja o despertar, em Acorde!, convida novos adeptos para uma rede subversiva de disseminação de memes e elaboração de táticas midiáticas ${ }^{3}$ - como manifestações orgiásticas frente à globalização ou ao escambo monetário.

\footnotetext{
2 Apodrece e vira adubo surgiu em 2000 no formato de fanzine impresso, com duas edições publicadas. Criado como suplemento literário da banda Malditos Ácaros do Microcosmos, cujos integrantes assumiam personas ácaros e mascarados entoavam a condenação da humanidade. A saga é evidenciada na ópera-rock Malditos somos nós tentando ser nós mesmos, exibida no Festival de Teatro de Curitiba em 2001. Apodrece e vira adubo ganha forma online em 2002. Endereço atual: http://apodrece.arquiviagem.net.

3 Para o movimento Critical Art Ensemble, mídia tática é "situacional, efêmera e autoterminal. Ela incentiva o uso de qualquer meio de comunicação para envolver um contexto sociopolítico em particular, a fim de criar intervenções moleculares e choques semióticos que, coletivamente, poderiam diminuir a intensidade da cultura autoritária" (2013, tradução nossa).
} 
Em Trace seu eu-vitoriamario, é ofertado um campo de inscrição voltado a autorretratos e assinaturas. Seria isso o teste de filiação ou exame de multiplicação para seguir adiante? Nesse espaço, Vitoriamario cria uma espécie de jogo da reflexão, um diálogo permanente com seu eu-outro navegante. Paradoxalmente, o grafo em pixel sugere do ecrã um sudário cujo registro é impermanente. Os rastros toscamente delineados pelo aplicativo estão fadados ao apagamento a partir da desconexão com a página.

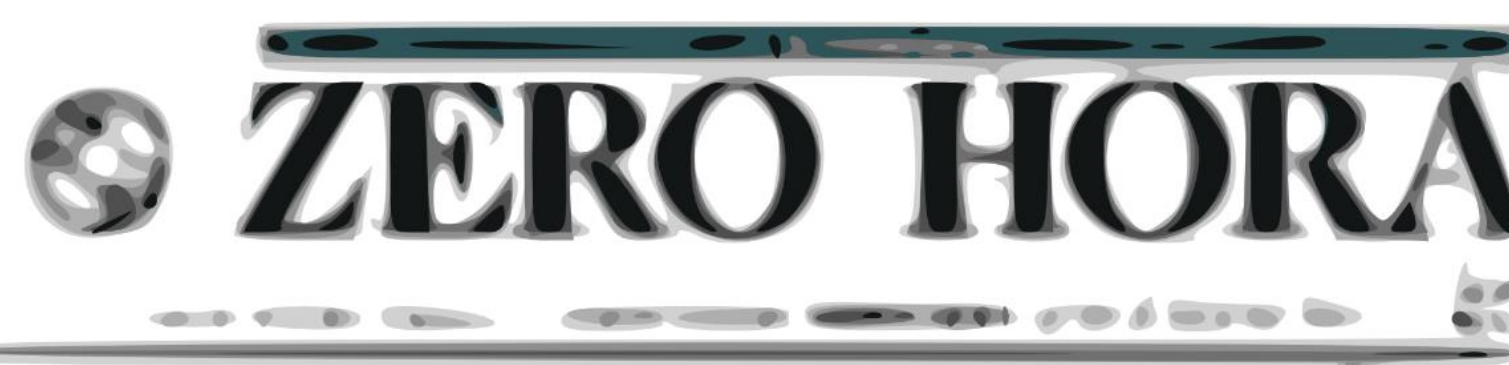

\section{Bruxo Vitoriamario é executado \\ em praça pública}
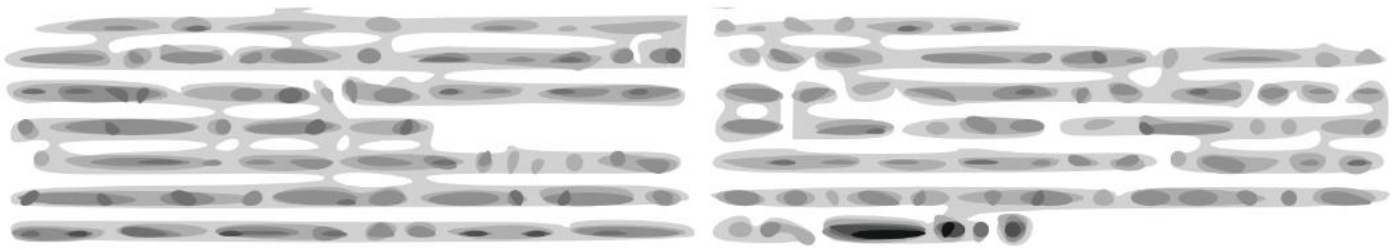

Figura 2: Vitoriamario. A morte do bruxo. 2001. Arquivo do autor

Nada Além de você fornece subsídios para saber afinal do que se trata Vitoriamario. O texto explicita seu jogo de eus - eu-artista, eu-viajante, euvitoriamario e ainda um eu-narrador homônimo, um curioso pesquisador que foi contemplado com um spam à maneira de Mallarmé enviado por Vitoriamario: 
Dias atrás um estranho e-mail caiu na minha caixa postal. 0 remetente se autointitulava Vitoriamario. Pelo fato de ser meu/minha xará despertou-me atenção redobrada. 0 e-mail apresentava o seguinte título Vazio - Empty

- Vide e o conteúdo era uma página em branco (2002c).

0 que a tela em branco sugere? Com 0 vide (mensagem em branco) Vitoriamario abre um diálogo ao plano de seu eu-invisível. A proposição opera na indução da dúvida, será um erro de mensagem? Quem remete? A quem destina? Vitoriamario remete àquele que destina, porém, espera algum retorno?

Em outro trecho do mesmo texto, o eu-narrador articula diversas referências artístico-ativistas, sugerindo interlocutores potenciais:

O tal pseudônimo está diretamente ligado ao atual ativismo político-cultural de ponta encontrado na rede: Zapatismo, Hackerismo, Critical Art Ensemble, Luther Blissett, Hakim Bey, Zerowork, Nadaismo, entre outros ismos de inúmeros istmos contraculturais (2002c).

Nessas afinidades conceituais, Vitoriamario encontra seu jogo retórico. Um jogo incisivo, cujo discurso não hesita, toma de assalto o leitor ao estabelecer a aporia: "Vitoriamario é você!". Em reação ao texto Nada além de você, o leitor Hélio Fernando comenta: "Vitoriamario seria uma possível abnegação do eu que é submetido a info-afirmação alheia...". Assim, Vitoriamario ecoa na busca pelo outro:

Hoje não fiz nada. Quem sou? Quem se importa? O que importa é: Quem é você? Perdido na frente de pixels e uma caixa cheia de pó de fósforo procurando respostas para sua existência? Quer seu rosto neste espelho? Quer sua foto = a minha foto? Um nome um pai perverso um útero fálico pra se guardar. (...) Não me venha com leis dialéticas de sentido. Seja-me. Já! Apareça Vitoriamario! (2002c).

Vitoriamario expõe uma relação que tensiona o eu-outro em sua inversão, estendendo o espaço de fala ao abismo da impermanência.

4 Comentário à publicação Nada além de você no sítio CMI-Brasil. Centro de Mídia Independente. Disponível em: http://www.midiaindependente.org/pt/red/2002/09/37153.shtml. Acesso em: 03 abr. 2016. 

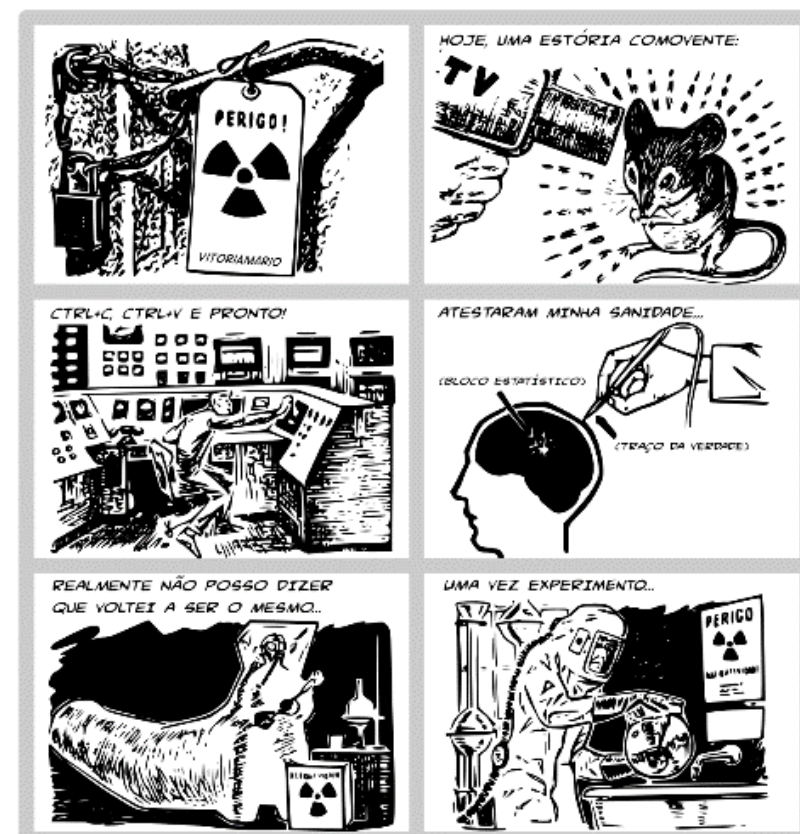

MULTIPLIOUELME A CADA LABIRETTO.

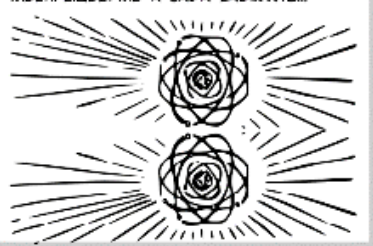

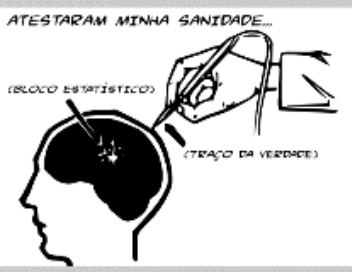
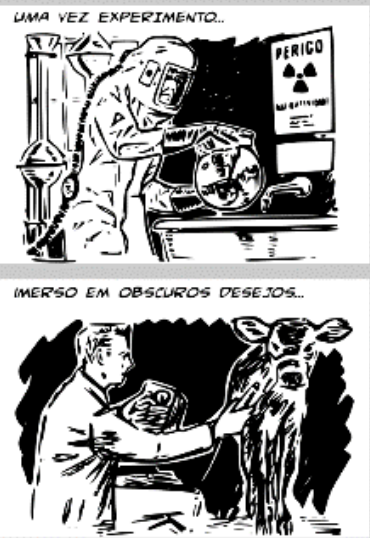
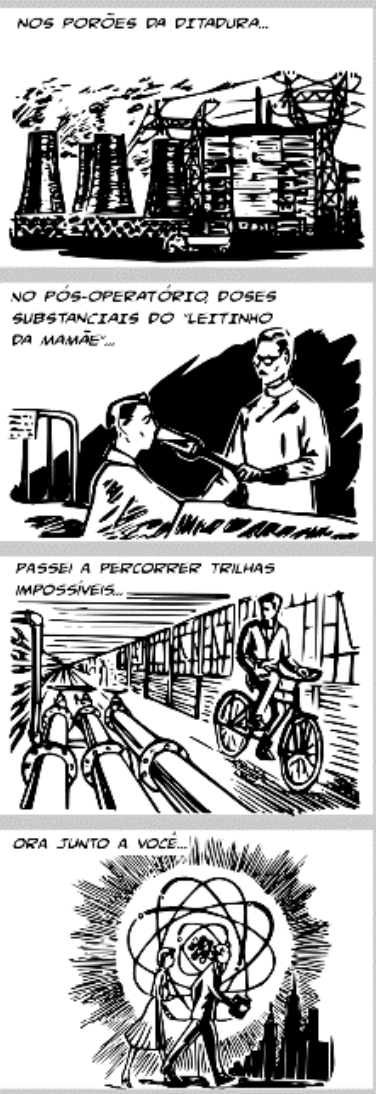

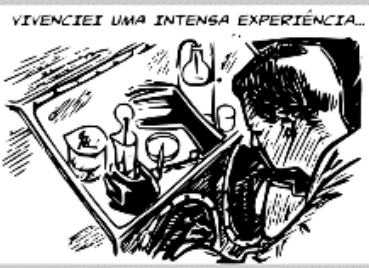

DTZTAM SER EU MESMO MAS PERCEBTA

QUE ALGO HAVTA MUDADO

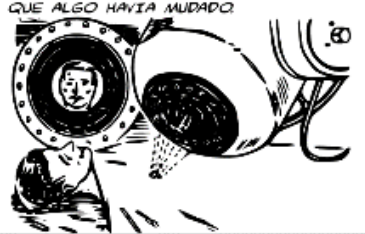

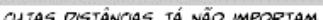

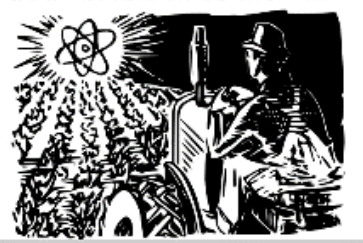

ORA NA FATÍLICA SEPARAÇÃO

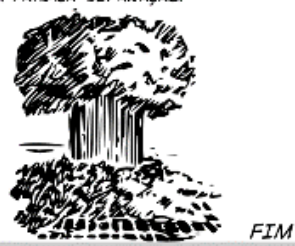

Figura 3: Vitoriamario. Perigo!. 2001-2016. Versão digital. Arquivo do autor.

Em suas ladainhas, Vitoriamario reconhece seu contrassenso e fracasso, dos quais se vale na poética dos encontros. Atrair e desprender-se da órbita de contato são questões presentes em Perigo!, uma história em quadrinhos derivada de ilustrações de um opúsculo sobre química nuclear ${ }^{5}$ em que Vitoriamario aponta para a inevitável separação (Figura 3). A criatura reivindica emancipação do criador, momento em que a relação se abre à bifurcação. Em sentido correlato, o eu-artista duvida da pertinência daquilo que elabora por intuição ou autoengano, uma espécie de tropeço, de esbarro, instante em que o sismo cisma, em que o projeto balança. 0 extremo da experiência seria um ponto de interrupção, curto-circuito, rompimento de elo, ruptura. Perigo! entrevê aquilo que escapa das mãos,

5 A referência do livro foi perdida no processo de recorte e colagem. Mantém-se publicada em página web somente a versão digital da história em quadrinhos. 
momento em que o vínculo caminha ao seu desenlace, quando o processo se inclina à entropia. Alude à recorrência da norma como fatídica lei que freia o devaneio. Acentua a ironia da vida frente ao que não deu certo. 0 que resta dos desenlaces dos imbróglios apodrece para então retornar como potência, como adubo. Em seu detalhe consta a perspicácia como atitude de revés, a sabedoria de saber deixar. A morte aparece como chama ao desconhecido, a guiar por novos caminhos, a soprar outras arquiviagens.

Vitoriamario é crítico de sua própria condição e do mundo no qual está imerso. Quebra a nostalgia com escárnio. Embaralha as certezas da verdade e daquilo visto como promissor. Ele se manifesta pelo esdrúxulo e pela dúvida daquilo que se afirma como verdade. Em sua fanfarrice, perderse faz parte do caminhar. Em Rituais eletroacústicos, um álbum musical com mais de sessenta faixas, o estapafúrdio se faz presente, zomba: "Os Estados Unidos dominam o planeta e essa estátua é homenagem ao grande líder deles...". O release de um de seus grupos musicais, denominado Rádio Macumba, menciona que a comunidade Vitoriamario pode ser definida como:

(...) uma comuna de anarquistas, que desistiram da fatalidade de tornaremse teóricos acadêmicos para viver da pesca e horticultura de subsistência, conquistando os nativos da região com suas performances, festas e artesanato, estimulando a criatividade e aprendendo com a humildade do pessoal local (2001).

Nessa ocasião, Vitoriamario chegou a ser responsabilizado por autoridades locais pela realização de transmissões piratas de mensagens subversivas em alta frequência, sendo uma das pautas a tentativa de construir uma linguagem desprovida de ego - estranhamente o único pronome usado seria o eu.

Uma das séries de vídeos de Vitoriamario disponíveis em Apodrece e vira adubo é fruto de pesquisas em acervos audiovisuais. Talento Nacional, Dança Baliza, HIVHS e Rumo ao desconhecido derivam da apropriação e 
edição de registros, propagandas e programas de televisão retirados de mídias obsoletas como o VHS. Can. 02 e A cópia a partir do real são vídeos realizados pela experimentação com dois videocassetes. Entre os assuntos estão comemorações cívicas, cursos de capacitação profissional, programas jornalísticos, cultura de massa, padronização da linguagem audiovisual, discursos desenvolvimentistas e tecnológicos proferidos no final do século XX.

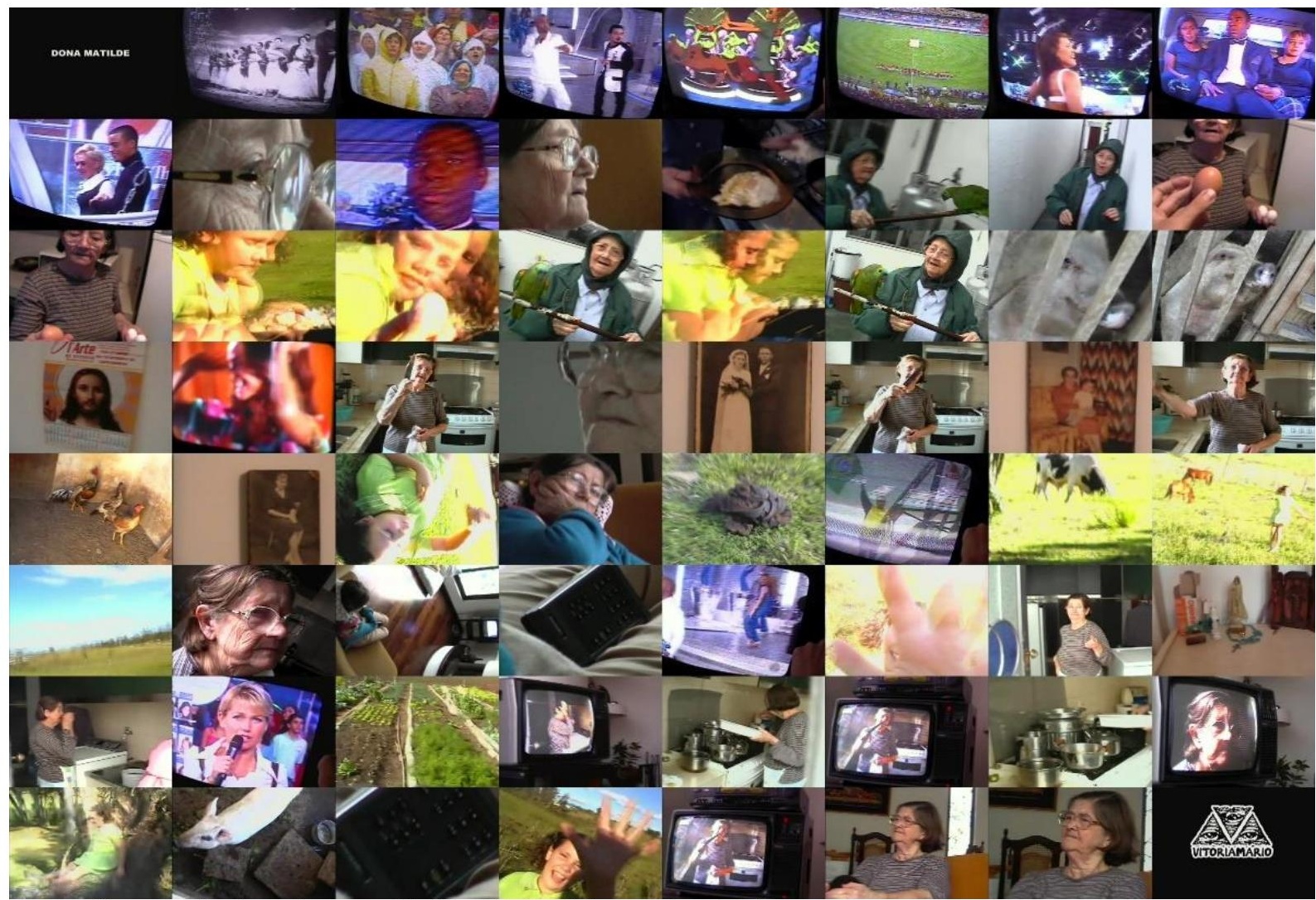

Figura 4: Vitoriamario. Dona Matilde. 2001. 64 frames. Arquivo do autor.

No videopoema Dona Matilde6 (Figura 4), Vitoriamario se apropria do poema A hipérbole do cabeleireiro-crocodilo e da bengala de autoria de Hans Richter, realizado colaborativamente com artistas dadaístas ${ }^{7}$. Nesse

6 DONA MATILDE. Colorido, 3 minutos, Brasil, 2001. O vídeo Dona Matilde foi laureado na primeira edição Concurso Nacional de Clipoemas, idealizado por Décio Pignatari, promovido pela Fundação Cultural de Curitiba e exibido na edição do Perhapiness em 2001.

7 Uma poesia cuja composição se caracterizava pelo revezamento dos poetas frase a frase em um processo automático e independente, não necessitando a linearidade ou subordinação de sentido. Esse método dadaísta foi denominado de Poesia Simultânea (Lima, 2012: 44). 
vídeo, Vitoriamario registra a leitura em voz alta do poema pela protagonista, que declama a seu jeito: "Nem a gramática, nem a estética, nem o Buda, nem o sexo (ops, o sexto) mandamento poderiam impedi-lo. O poeta cacareja, xinga suspira, gagueja (igual eu!!) ao seu bel-prazer". ${ }^{8}$ Novamente um jogo de espelhos em que Dona Matilde é homônimo ficcional do seu eu real, que ao se ver na tela da televisão reprova as escolhas de Vitoriamario. Como Denise Guimarães analisa:

A obra vale-se do uso quase exclusivo da câmera para explorar parodicamente os clichês e os lugares-comuns da linguagem da televisão, efetuando uma crítica de seus efeitos sobre as pessoas simples. (...) Imagens de uma infância nostálgica no campo efetuam o contraponto entre o real - tecnológico e restrito - e o imaginário, que aparece ligado a uma vida em contato com a natureza. Há uma organização linear das cenas, uma sequência dos episódios centrais, com algumas inclusões de imagens de programas de TV, bem populares, cujo efeito sobre a personagem é hipnótico. Ao final, Dona Matilde, uma senhora idosa, que acreditava ser real tudo o que via na telinha, vai ver-se e ouvir-se na TV; e a câmera registra o impacto desse evento sobre ela, com a troca de papéis na subversão da ideia de espetáculo. (...) Os programas citados visualmente constituem protótipos da representação visual e da imagem da mídia: imagem onipresente e invasora, imediatamente associada à TV de forte apelo popular e conformadora do repertório de Dona Matilde. A heterogeneidade das imagens (os múltiplos materiais que as compõem) articulam suas significações específicas entre si, para a produção da mensagem global veiculada. (2004: 289-290).

Dona Matilde, diferentemente da série de apropriações de arquivos e mídias em VHS, se alinha com os vídeos Zero Kelvin, O Anti-Édipo e Rádio Macumba, elaborados a partir de roteiros, narrativa, planos sequenciais, captura de imagens, minuciosa edição e uso de efeitos visuais.

Em outra vertente, buscando explorar os meios digitais, Vitoriamario elaborou uma série de mensagens gráficas/textuais baseadas em código de programação HTML. Isto não é uma mensagem, Qual a diferença?,

8 Poema de Hans Richter na íntegra: A hipérbole do cabeleireiro-crocodilo e da bengala / nem o postilhão de linguagem nem o hexâmetro nem a gramática / nem a estética nem o Buda nem o sexto mandamento deveriam impedi-lo / o poeta cacareja, xinga, suspira, gagueja canta à tirolesa e ao seu bel-prazer / seus poemas são como a natureza: ninharia / são tão preciosos para ele como uma retórica sublime / porque na natureza cada partícula / é tão bela e importante quanto uma estrela / e os homens é que se julgam no direito de determinar / o que é belo e o que é feio. (Richter, 1993) 
Enúmeros, Emovie, Múltipla escolha, Babel, Caolho, Arte ou vagalumes são algumas dessas spamarts. As mensagens foram encaminhadas via correio eletrônico para uma vastidão de endereços e hoje compõem 0 arquivo Apodrece e vira adubo.

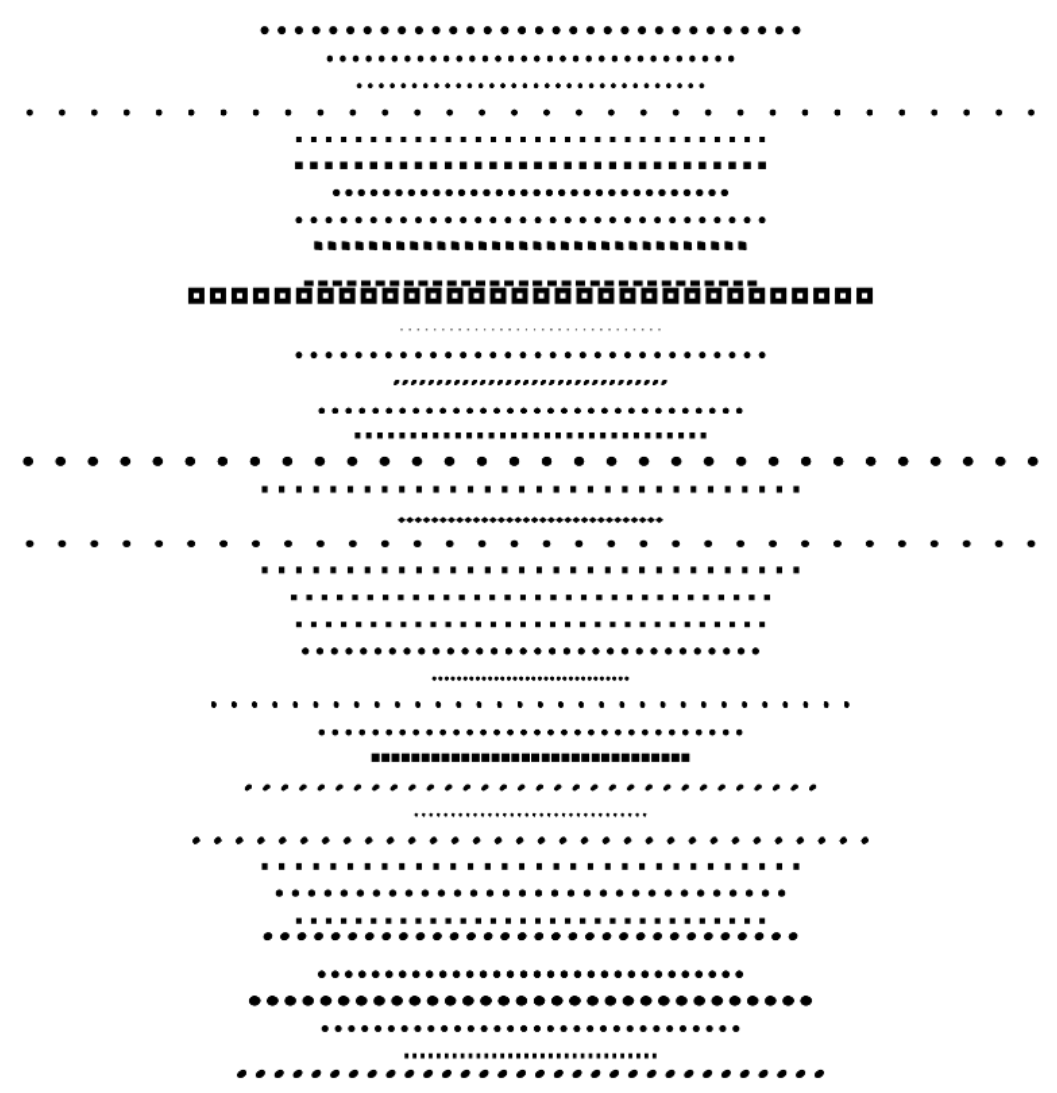

Figura 2: Vitoriamario. 32 pontos $x 231$ tipos. 2002. Extrato. Arquivo do autor

Em 32 pontos $X 231$ tipos Vitoriamario explora as múltiplas possibilidades de transformação aleatória ou involuntária do arquivo, nas quais uma mensagem eletrônica transcorre desde sua origem (remetente) até atingir o destinatário (Figura 5). Os desvios composicionais acontecem, em relação à mensagem original, por meio de variações de comportamento e configurações estabelecidas em cada computador ou aparelho móvel de uso pessoal, ou nas possíveis plataformas de correio eletrônico receptoras. 
O propositor apenas joga com a aleatoriedade de padrões estéticos de programação predeterminados, que em seu conjunto, de algum modo, influenciam o resultado final. A soma de circunstâncias e de elementos (não) intencionais é que forma a mensagem. ${ }^{9}$

Essa proposição evidencia o interesse de Vitoriamario por aquilo que foge de seu domínio. O que importa é justamente a falta de controle estético implícita por uma indeterminação de resultados ou consequências advindas do processo, ou ainda o controle extremo do mesmo pelas pré-codificações dos sistemas enredados. A trama formada por múltiplas circunstâncias gera variadas mensagens, organização de pontos diferenciados, além do previamente elaborado. A partir disso, os resultados são heterogêneos (Deleuze; Guattari, 2011). Contudo, cada destinatário recebe somente a mensagem que sua máquina ou programa formatar. Uma mensagem via correio eletrônico é enviada para aproximadamente dez mil endereços abertos em aparelhos com softwares e configurações diferenciadas, na qual cada circunstância que determina essa mensagem é tão elementar como um ponto - forma a priori adotada pela ideia da multiplicidade das reticências ou talvez por sua carga minimal e zerodimensional (Flusser, 2008). Vitoriamario utiliza-se das fontes disponíveis em seu computador para representar 32 pontos enfileirados na horizontal, linha a linha até seu esgotamento. O resultado é um pontilhismo padronizado, um poema sistemático que atesta/protesta pontualmente os esquadrinhamentos estéticos e massificações culturais condicionados aos aparatos científicos, tecnológicos e industriais.

\section{Levante sobre poeira}

O levante se instaura no instante em que a poeira se exalta. Se a arquiviagem se dá pela prática da deriva, arquiviajar em Apodrece e vira adubo é levantar a poeira do eu-múltiplo do artista, visitar seu espaço de

90 conjunto das empresas (de hardware ou software), servidores, profissionais de informática, bem como o próprio usuário de um endereço eletrônico. 
arquivo a fim de sondar resquícios, perceber rastros, apurar restos. Esse gesto implica embrenhar-se na materialidade (mesmo que em fragmento), na ideia latente (pela não realização ou mesmo pelo apagamento) e no próprio esquecimento. Ao arquiviajante cabe analisar ou conectar as variáveis que acometem a absurda, e não menos necessária, existência de Vitoriamario. Apodrece e vira adubo surge como um espaço rizomático de invenção, em sua entropia não escapa ao acúmulo, ora em repetição, ora em sobreposição, ora em baderna - poeira que se agita na medida das escolhas da arquiviagem. Vitoriamario forja seu próprio baú, repleto de elementos fabulosos, um baú sem fundo e que se preenche na medida em que outros Vitoriamario o vasculham e toma sentido no risco implícito em acionar memórias, explorar a imaginação e tramar mundos.

Nesses atravessamentos, constato um paradoxo. Tais aberturas emergem a partir daquilo que invariavelmente as interrompe. Os projetos abandonados, as frases malditas, os abortos intencionais, os forçados e os acidentais - neles curto-circuitam tempos e espaços, redobrados em arquivo. Ao se estabelecer uma trajetória, surgem aberturas e atravessamentos. Por eles é que Vitoriamario invade a atenção, sem pedir licença, chega, marca e abandona - como fumaça que se esvai, princípio instável que não se ancora. Seu cálculo se rende ao desvio. Em potência se eleva na medida de sua redefinição, na variação de cada ciclo. Vitoriamario intui ao excêntrico ou atrai por magnetismo. Um modo de ser que ao chegar retorna, que insiste em desistir, nesse ciclo, em cada recomeço, varia em reabertura para outras atitudes inconsequentes.

O eu-arquivo Vitoriamario se propõe como oscilação. Quando o artista arrisca, em voo percorre o extemporâneo - movimento amplo, que então retorna em arte. Algo que não se vê, mas está, como algo que apodrece e vira adubo. 


\section{Referências}

AGAMBEN, Giorgio. O que resta de Auschwitz: o arquivo e a testemunha (Homo Sacer III). Tradução Selvino J. Assmann. São Paulo: Boitempo, 2008.

ANTOCEVEIZ, Juliano de Paula. Arte marginal: a arte fora dos eixos. Monografia de Especialização. Orientador Prof. Alberto Ireneu Puppi. Curitiba: Embap, 2005.

BARTHES, Roland. O rumor da língua. Tradução Mário Laranjeira. Prefácio de Leyla Perrone-Moisés. São Paulo: Brasiliense, 1988.

BATAILLE, Georges. A parte maldita. Rio de Janeiro: Imago, 1975.

BECKETT, Samuel. O inominável. Rio de Janeiro: Nova Fronteira, 1989.

BLANCHOT, Maurice. O livro por vir. Tradução Leyla Perrone-Moisés. São Paulo: Martins Fontes, 2005.

BLISSETT, Luther. Guerrilha psíquica. São Paulo: Conrad, 2001.

CARVALHO, Flávio de. Experiência n.2: realizada sobre uma procissão de Corpus Christi: uma possível teoria e uma experiência. Rio de Janeiro: Nau, 2001.

CRITICAL ART ENSEMBLE. Tactical Media. 2013. Disponível em: $<$ http://www.critical-art.net/TacticalMedia.html>. Acesso em: 18 abr. 2016.

DELEUZE, Gilles; GUATTARI, Félix. Mil platôs: capitalismo e esquizofrenia 2, vol. 1. Tradução Ana Lúcia de Oliveira, Aurélio Guerra Neto e Celia Pinto Costa. 2 ed, São Paulo: Editora 34, 2011.

FIGUEIREDO, Eurídice. Roland Barthes: da morte do autor ao seu retorno. Revista Criação e Crítica. São Paulo, n. 12, p.182-194, jun. 2014. Disponível em: <http://revistas.usp.br/criacaoecritica>. Acesso em: 13 abr. 2016.

FLUSSER, Vilém. O universo das imagens técnicas: elogio da superficialidade. São Paulo: Annablume, 2008.

FOUCAULT, Michel. A arqueologia do saber. 7 ed. Rio de Janeiro: Forense Universitária, 2009.

O que é um autor? Tradução António Fernando Cascais e Eduardo Cordeiro. Lisboa: Vega/Passagens, 1992.

GOLDSMITH, Kenneth. Uncreative writing: managing language in the digital age. New York: Columbia University Press, 2011.

GUATTARI, Félix. Revolução molecular. Pulsações Políticas do Desejo. São Paulo: Brasiliense, 1987.

GUIMARÃES, Denise Azevedo Duarte. Poesia visual \& Movimento: da página impressa aos multimeios. Tese de Doutorado. Orientador Dr. Édison José da Costa. Curitiba: Universidade Federal do Paraná, 2004. 
LIMA, Rodrigo Nogueira. A situação construída. Dissertação de Mestrado. Orientador Dr. Carlos Roberto Monteiro de Andrade. São Carlos: Universidade de São Paulo, 2012.

PELBART, Peter Pál. O tempo não-reconciliado. São Paulo: Perspectiva FAPESP. 1998.

RICHTER, Hans. Dadá: arte e antiarte. Tradução Marion Fleischer. São Paulo: Martins Fontes, 1993.

SEBALD, W. G. Austerlitz. Tradução José Marcos Macedo. São Paulo: Companhia das Letras, 2008.

VITORIAMARIO. Entrevista com o pirata Vitoriamario. In: Apodrece e vira Adubo. 2002a. Disponível em: <http://apodrece.arquiviagem.net/ameent.html>. Acesso em: 03 abr. 2016. Manifesto Vitoriamario. In: Apodrece e vira adubo. 2002b. Disponível em: <http://apodrece.arquiviagem.net/ameman.html>. Acesso em: 03 abr. 2016.

Nada além de você. In: Apodrece e vira adubo. 2002c. Disponível em: <http://apodrece.arquiviagem.net/amenad.html>. Acesso em: 03 abr. 2016.

Rádio Macumba. In: Apodrece e vira adubo. 2001. Disponível em: <http://radiomacumba.arquiviagem.net/>. Acesso em: 18 abr. 2016.

Qual seu real valor? In: Apodrece e vira adubo. 2002d. Disponível em: <http://apodrece.arquiviagem.net/ 